\title{
Agenesis of female internal reproductive organs, the Mayer- Rokitansky-Küster-Hauser syndrome
}

\section{0-years of experience with its management in a single centre}

\author{
Sysak $\mathrm{R}^{1}$, Bluska $\mathrm{P}^{2}$, Stencl $\mathrm{P}^{1}$, Klein $\mathrm{M}^{3}$, Varga $\mathrm{I}^{3}$ \\ 1st Department of Gynecology and Obstetrics, Faculty of Medicine, Comenius University in Bratislava \\ and University Hospital Bratislava, Slovakia. ras.sysak@post.sk
}

\begin{abstract}
OBJECTIVES: Mayer-Rokitansky-Küster-Hauser (MRKH) syndrome is the most common cause of uterine and uterine tubes absence/underdevelopment and the second most common cause of primary amenorrhea. It is characterized by a congenital agenesis of the uterine tubes, uterus, cervix, and upper part of the vagina. This study presents our 10 years of experience with the diagnostics and therapeutic management of patients with MRKH syndrome. We also focused on the description of anatomical deviations of the female reproductive organs.

MATERIALS AND METHODS: We studied a cohort of 16 patients hospitalized with MRKH syndrome between 2011-2020. We analysed the age at diagnosis, clinical signs and symptoms, diagnostic techniques, methods of neovagina creation, and anatomical anomalies of the female reproductive organs.

RESULTS: The mean age of our patients at the time of diagnosis was 16.75 years. The most frequent clinical manifestations were primary amenorrhea (56.25\%), pelvic pain (31.25\%) and coitus-associated problems. We used two methods of neovagina creation. In six patients we used the non-surgical Frank's dilators method. The vaginal length at the beginning of the dilation was $1.5-2 \mathrm{~cm}$. In 4 patients the vaginal length was under $1 \mathrm{~cm}$, so we performed surgical neovagina creation using the laparoscopic Vecchietti method. An-other two patients could create the vagina via regular sexual intercourse. Based on magnetic resonance imaging and ultrasound examination, the following anomalies were observed: complete agenesis of the uterus (50\% of cases), fibrous band (25\%) and rudimentary uterus $(25 \%)$.

CONCLUSIONS: Satisfactory results in the attempt to create a neovagina can be obtained by both nonsurgical and surgical methods. Modern medicine provides many therapeutic measures, which make it possible for the affected women to have a normal sexual life (Tab. 1, Fig. 3, Ref. 37). Text in PDF www.elis.sk KEY WORDS: Müllerian agenesis, Mayer-Rokitansky-Küster-Hauser syndrome, congenital anomalies of uterus, diagnosis, treatment, classification discrepancy.
\end{abstract}

\section{Introduction}

Development of the female internal reproductive organs is a complicated process from several embryonic perspectives. The first important aspect to consider is the fact that the primordia of both the male and female reproductive organs start to develop in each embryo regardless of sex. Both sets of ducts develop on the surface of the mesonephros during a period referred to as the indifferent stage of sexual development. In females, the absence

${ }^{1} 1$ st Department of Gynecology and Obstetrics, Faculty of Medicine, Comenius University in Bratislava and University Hospital, Bratislava, Slovakia, ${ }^{2}$ Rádiológia, Ltd., Bratislava, Slovakia, and ${ }^{3}$ Institute of Histology and Embryology, Faculty of Medicine, Comenius University in Bratislava, Slovakia

Address for correspondence: R. Sysak, MD, PhD, 1st Department of Gynecology and Obstetrics, Faculty of Medicine, Comenius University in Bratislava and University Hospital Bratislava, Antolská 11, SK-851 07 Bratislava, Slovakia. Phone: +421.2.68672726

Acknowledgement: This research was funded by the Slovak Research and Development Agency grant number APVV-18-0499. of anti-Müllerian hormone and SRY gene conditions the regression of the Wolffian ducts and permits further differentiation of the Müllerian ducts. Secondly, after the regression of the Wolffian ducts, the paired Müllerian ducts must undergo a partial fusion, an extremely important process in the proper development of the unpaired uterus and upper two thirds of the vagina. This fusion is followed by the resorption of the midline fused segments in the uterus, uterine cervix and upper vagina. The non-fused superior aspect of each Müllerian duct develops into the left and right uterine tube (1-3). This complicated development of the Müllerian ducts is controlled by various genes, for instance Pax2, Lim1 (Lhx1), Emx2, Wnt4, or Wnt9b. Their mutations can result in partial or complete agenesis of the Müllerian ducts, which results in underdevelopment or even non-development of the uterus, upper portion of the vagina, and, in some cases, the uterine tubes (4). This Müllerian agenesis is also known as Mayer-Rokitansky-Küster -Hauser (MRKH) syndrome and has a reported incidence of one in 4,000-5,000 female live births (5).

MRKH syndrome can be classified into two types. In the typical form, the caudal parts of the Müllerian ducts are affected in a 
symmetric pattern. This results in the absence of the uterus and the upper portion of the vagina, while the uterine tubes remain normal and no extragenital abnormalities are present. The atypical form in characterized by asymmetric hypoplasia of the uterine primordia, with or without dysplasia of the uterine tubes, and frequent co-existence of renal and ovarian defects (6). MRKH syndrome usually manifests during adolescence with primary amenorrhea, but can be delayed until adulthood with infertility or sexual dysfunction as the signs of the condition (7).

This study presents our 10 years of experience with the diagnostics and the following therapeutic management of the patients with the MRKH syndrome. All the patients were examined at the largest department of gynaecology and obstetrics in the Slovak republic (circa 5.5 million inhabitants). We also report the descriptions of anatomical deviations of the female reproductive organs found in our patients.

\section{Patients and methods}

We studied a cohort of 16 consecutive patients, who had been investigated for MRKH syndrome at the Department of Gynaecology and Obstetrics, Faculty of Medicine, Comenius University in Bratislava and University Hospital Bratislava, Slovakia, between January 2011 and December 2020. Informed consent was obtained from all the patients involved in the study. We analysed the age at diagnosis, clinical signs and symptoms, techniques used in the diagnostic process, age of the consultation for neovaginal creation, methods of neovagina creation, and anatomical anomalies of the female reproductive organs. Success of treatment was defined by creation of a neovagina that would enable normal sexual intercourse.

\section{Results}

Consultations and examinations were performed in the presence of at least one, but preferably both parents. We carried out the consultations in multiple sessions. At the beginning of the first session, during which the definitive diagnosis was established, we focused on detailed anatomical description of the syndrome and its characteristics. Discussing the negative aspects of the condition, we gently formulated the question regarding the inability to have sexual intercourse. Promptly after these types of questions, we tried to give the patients hope by explaining the modern options of neovagina creation - both surgical and non-surgical methods. From our experience, the first session is not suitable for a detailed explanation of the procedure and the necessity of patient cooperation during the neovagina formation. This is discussed only when the time comes. One of the greatest psychological distresses for the patient is the realization that due to the absent uterus, they won't be able to bear a child. We tried to give the patients hope in this regard by addressing this with an adoption, which is the most viable option in Slovakia. We also informed the patients about the gestational surrogacy. However, the legal aspects of gestational surrogacy in the Slovak Republic are not resolved. We always try to give our patients hope that they will be capable of having normal sexual intercourse and will be allowed to raise a child. This stra- tegy was perhaps the reason, why we didn't encounter any serious psychological problems in our cohort.

Age

The age range in our cohort was 9-20 years at the diagnosis. The mean age was 16.75 years.

\section{Clinical signs and symptoms}

The most frequent clinical manifestation of the MRKH syndrome, which led the patients to contact a gynaecologist, was primary amenorrhea. It occurred in nine cases (56.25\%). The age range for this sign was 16-19 years. The second most frequent clinical manifestation was pelvic pain. It occurred in five cases (31.25\%). The age range for this symptom was 9-18 years. Coitusassociated problems (reflexive spasm of the vaginal opening and the ensuing difficulty of penile-vaginal penetration) occurred in one 20-year-old patient. This patient hadn't been concerned with primary amenorrhea until that time. The last patient of our cohort was diagnosed with MRKH syndrome upon examination for a non-specific sign of the syndrome. A paediatric gynaecologist examined this 10-year-old with suspected vulvitis acuta. During visual inspection of the external genitalia, imperforate hymen was suspected. Subsequent ultrasound examination revealed absence of the uterus.

\section{Diagnostic techniques}

The basic diagnostic method for MRKH syndrome is ultrasound examination. It was performed in all 16 patients in our cohort. In seven patients (37.5 \%), definitive diagnosis was established by ultrasound examination exclusively. In another seven patients, the diagnosis was established by a combination of ultrasound and magnetic resonance imaging (MRI). MRI scan was performed in case of inconclusive ultrasound findings, but also to search for associated anomalies in other organ systems, if a patient presented with additional signs or symptoms, for example low back pain or other symptoms indicating a possible issue in the organs of the urinary system. One 18-year-old patient with a pelvic pain was diagnosed during a diagnostic laparoscopy and one 17-year-old patient with a primary amenorrhea was diagnosed by computer tomography (CT) scan. These two patients had not been examined by a gynaecologist before and had not previously undergone gynaecologic ultrasonography. In both cases, the patients presented with acute abdomens. The MRKH syndrome was diagnosed unexpectedly during diagnostic laparoscopy or CT scan. This highlights the fact that MRKH syndrome can be occasionally diagnosed incidentally.

\section{The age of consultation for neovaginal creation}

From the whole cohort, 13 patients underwent consultations for neovaginal creation, accounting for $81.25 \%$ of cases. The age range of these patients was 17-23. The majority (9 cases, $56.25 \%$ ) were between 17-19 years of age at the time of consultation coinciding with the time of coitarche. Before treatment, we discussed treatment course, complications, and benefits with all the patients in detail. Every patient was offered a psychological consultation. 

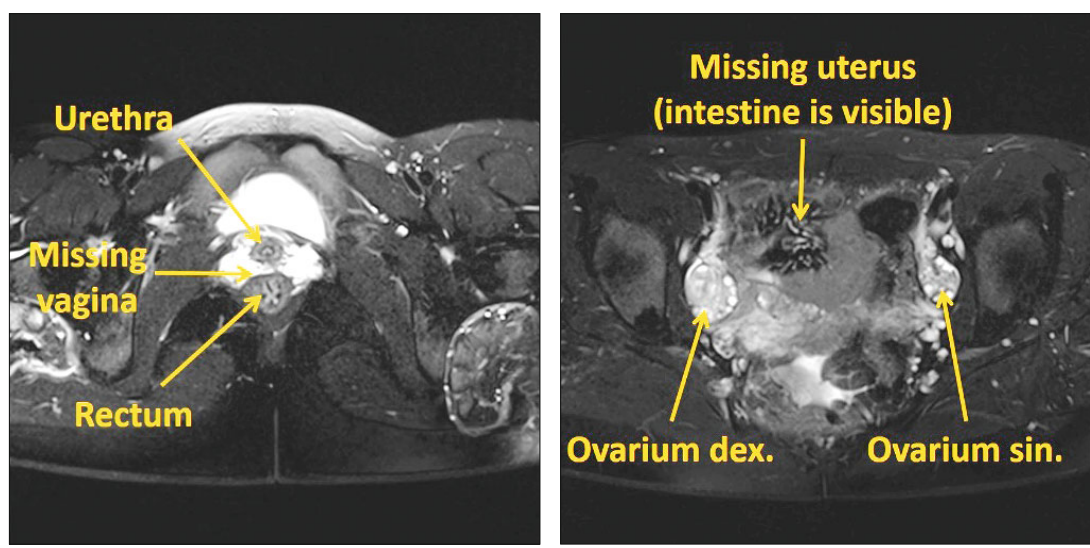

Fig. 1. Transverse sections of a magnetic resonance scan of the lesser pelvis in a patient with MRKH syndrome. The uterus and upper vagina are absent.
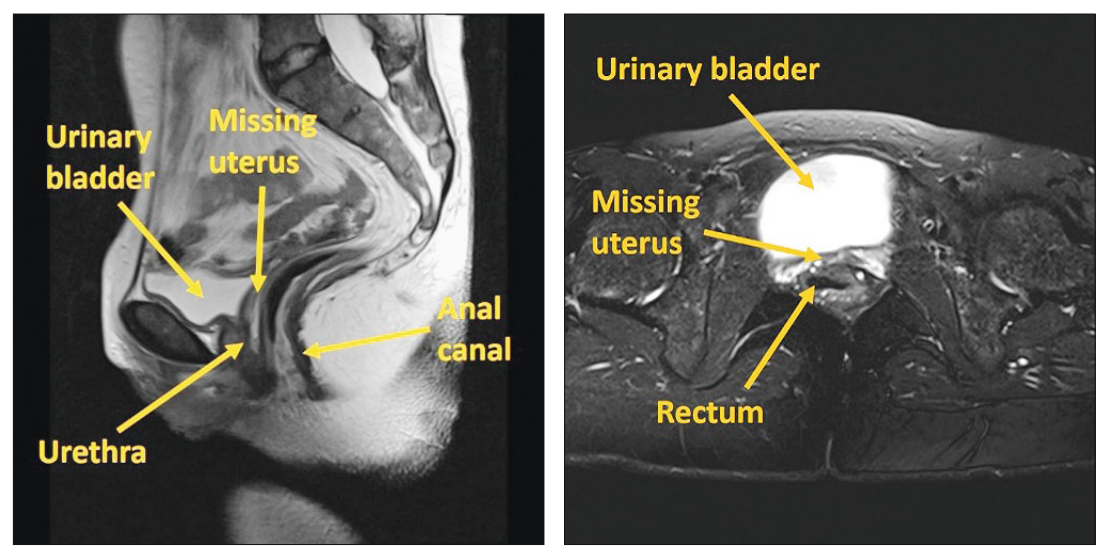

Fig. 2. Sagittal and transverse sections of a magnetic resonance scan of the lesser pelvis in a patient with MRKH syndrome. The uterus is absent.
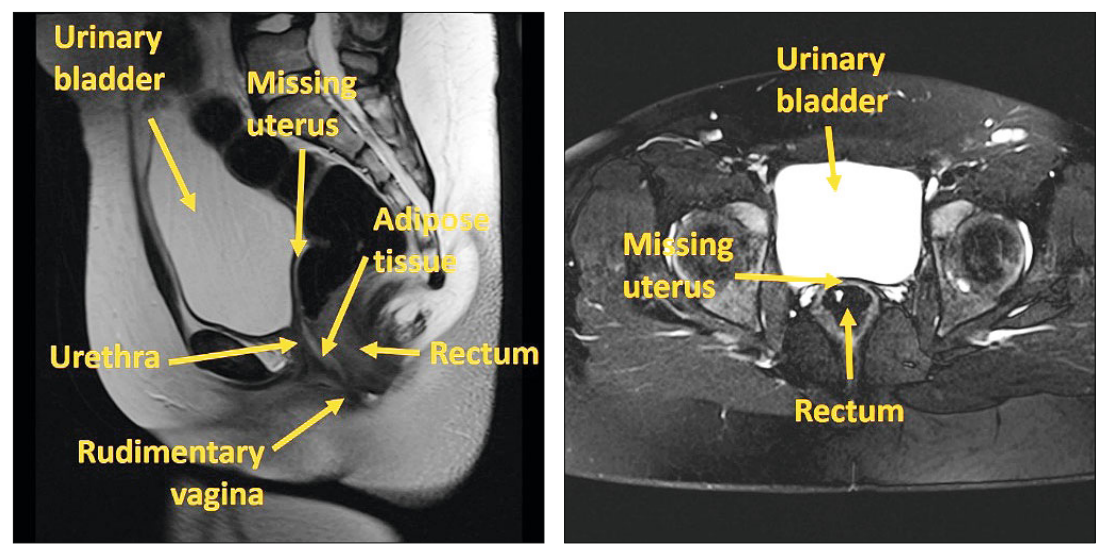

Fig. 3. Sagittal and transverse sections of a magnetic resonance scan of the lesser pelvis in a patient with MRKH syndrome. The uterus is absent.

Seventy-five percent of the patients accepted this offer, $25 \%$ refused it. The vaginal length was between $1-2 \mathrm{~cm}$. From the three patients, who didn't undergo consultation, the first was 9 years old, the second was 10 years old, and finally the third (a 21-year-old) hadn't considered starting her sex life yet.
The methods of neovagina creation

In six patients ( $37.5 \%$ ) we chose a nonsurgical Frank's dilators method. The vaginal length at the beginning of the dilation was $1.5-2 \mathrm{~cm}$. In four patients (25\%) the vaginal length was under $1 \mathrm{~cm}$, so we chose to perform surgical neovagina creation with a traction vaginoplasty using the laparoscopic Vecchietti's method. In summary, from the 13 patients, who went through the consultation for neovagina creation, 10 patients underwent the procedure (62.5\%). From among the three patients, who decided against the procedure, two were capable of creating the vagina via a regular sexual intercourse. We have no information about the last patient in this regard.

The average length of the vagina in the patients, who underwent the Frank's method was $5 \mathrm{~cm}$ after 5 months of therapy and 8 $\mathrm{cm}$ after a year from the beginning of the therapy. This approach was a success in all our patients without any failures.

Regarding Vecchietti's method, in three patients the length of the vagina was $8 \mathrm{~cm}$ after 1 month from the surgery and in one case the length was $5 \mathrm{~cm}$ after 1 month from the surgery. After 2 months, the vagina was 8-9 cm long in all four cases and was fully epithelized. This approach was a success in all our patients.

None of the patients reported dissatisfaction with the treatment results of either of the two methods of neovagina formation. We can state that all the patients were satisfied with the treatment results.

Anatomical anomalies of the female reproductive organs

Based on MRI and ultrasound examination, the following anomalies were observed: complete agenesis of the uterus in eight cases (50\%) (Figs 1 - 3), fibrous band in four cases (25\%) and rudimentary uterus in four cases (25\%). The ovaries were normally developed and located in the normal position in 14 cases (87.5\%). In one case (6.25\%) the right ovary was absent. In one other case (6.25\%) both ovaries were dislocated cranially. This patient also had a rightsided dystopic kidney. These two patients with ovarian abnormalities were diagnosed with type II MRKH syndrome, the rest of the cohort had type I MRKH syndrome. None of the patients had a positive family history for MRKH syndrome. Table 1 summarizes the findings in our cohort of the patients with MRKH syndrome. 
Tab. 1. Summary of findings in our group of patients with the MRKH syndrome.

\begin{tabular}{|c|c|c|}
\hline Age at diagnosis & Range $=9-21$ years; Mean $=16.75$ years & \\
\hline \multirow{4}{*}{$\begin{array}{l}\text { Clinical symptoms leading to } \\
\text { gynaecological examination }\end{array}$} & Primary amenorrhea & $56.25 \%$ \\
\hline & Pelvic pain & $31.25 \%$ \\
\hline & Sexual dysfunction & $6.25 \%$ \\
\hline & Others & $6.25 \%$ \\
\hline \multirow{4}{*}{ Method of neovagina creation } & Repeated natural sexual intercourse & $12.5 \%$ \\
\hline & Non-surgical Frank's dilators method & $37.5 \%$ \\
\hline & Laparoscopic Vecchietti's method & $25 \%$ \\
\hline & No procedure (too young or other reasons) & $25 \%$ \\
\hline \multirow{3}{*}{ Morphological findings - uterus } & Complete agenesis of the uterus & $50 \%$ \\
\hline & Fibrous band instead of the uterus & $25 \%$ \\
\hline & Rudimentary uterus & $25 \%$ \\
\hline \multirow{3}{*}{ Morphological findings - ovaries } & Normal & $87.5 \%$ \\
\hline & Cranially dislocated ovaries & $6.25 \%$ \\
\hline & Agenesis of the right ovary & $6.25 \%$ \\
\hline
\end{tabular}

\section{Discussion}

MRKH syndrome, also known as Müllerian agenesis, is the most common cause of uterine absence/underdevelopment and the second most common cause of primary amenorrhea. It is characterized by a congenital absence of the uterus, cervix, and the upper part of the vagina in otherwise phenotypically normal 46, XX females $(8,9)$. MRKH syndrome is mainly sporadic; however, familial cases have been described (probably the autosomal dominant inheritance pattern, with incomplete penetrance and variable expressivity) (8). In the present article, we focused on the description of diagnostic methods and subsequent techniques of neovagina creation in our cohort of 16 patients, who have been diagnosed with MRKH syndrome over the last 10 years.

Although the MRKH syndrome is not as rare congenital anomaly, we still deem its level of scrutiny insufficient. After searching the PubMed database, which comprises more than 30 million citations for biomedical literature from MEDLINE, like science journals, and online books, we have found out that there are more than 5400 publications dealing with the congenital anomalies of the uterus. However, there are: 4 times more publications discussing the congenital anomalies of the gut or lungs, 6 times more publications focused on the kidneys, 9 times more focused on the brain, and 23 times more papers discussing the congenital heart defects. When we include only those publications on the uterine congenital anomalies, which discuss particularly the MRKH syndrome, the number shrinks to 800 . There are several possible reasons. Firstly, in line with our results, the condition is usually diagnosed in early adulthood (not directly after birth like the most of other congenital anomalies), and the agenesis of the uterine tubes, uterus and vagina is not life-threatening. On the other hand, the fertility problems, and the inability of having normal vaginal intercourse usually causes that the affected women experience a significant social deprivation and can lead to anxiety (10), depressive disorders (11) and sexuality-related distress, sexual dysfunction and painful intercourse (12). According to Hatim (7) a multidisciplinary approach including medical, psychological, and social support is essential for the complex management of the MRKH syndrome. Adequate information and sexual education are of utmost importance in preventing social-related complications of the MRKH syndrome. Modern medicine provides various options of infertility treatment for MRKH syndrome patients. One of the most promising are the in vitro fertilization (IVF) techniques coupled with gestational surrogacy $(13,14)$. This approach has shown to be successful in patients with Müllerian agenesis. Unfortunately, the legislation regarding the techniques of assisted reproduction and gestational surrogacy varies between countries, as this concept involves particularly complex medical, ethical, social, and legal issues. In some jurisdictions, these techniques are completely outlawed, so the patients in these countries must consider other, less controversial options like adoption (15). There are also novel experimental methods like uterus transplantation, with first reported live births from Brazil, Sweden or China (9, 16-18).

From the historical point of view, Matteo Realdo Columbo, an Italian anatomist of the 16th century, was the first to describe uterovaginal agenesis under the term "vulva rara". The MRKH syndrome is an eponym honouring great physicians and scientists of the 19th and 20th centuries, namely August Franz Joseph Karl Mayer, Karl von Rokitansky, Hermann Küster and Georges André Hauser, each of whom contributed to the discovery of this condition (19). We also shouldn't forget about a renowned German physiologist and embryologist of the 19th century, Johann Petrus Müller, whose teacher at the University in Bonn was the aforementioned August Franz Joseph Karl Mayer. Müller was the first to recognize the sexual differences and distinct embryonic origins of the ductus deferens and uterine tube, and described the role of the paramesonephric ("Müllerian") ducts in the process of the formation of the female reproductive organs (20). Despite the term "MRKH syndrome" has been widely recognized in literature, it has not been included in the 2nd edition of internationally accepted embryological nomenclature Terminologia Embryologica, which is supposed to contain the complete list of all congenital anomalies. Terminologia Embryologica mentions the anomalies of the uterine tubes (agenesis, atresia, or accessory tube), uterus (uterine agenesis and different morphological anomalies in the shape of the uterus), cervix uteri (cervical atresia) and vagina (vaginal atresia and agenesis), but separately of each other. There is no mention of any combination of these anomalies in this official nomenclature (21). According to some classifications, the MRKH syndrome belongs to a large group of disorders: agenesis or hypoplasia of the urogenital ridge (22). However, there is a discrepancy between different classification systems of the female genital anomalies, concerning either the opinions on the embryonic background of the anomaly, or the recommendation differences between The American Fertility Society and The European Society of Human Reproduction, as highlighted by Acién and Acién (23). These discrepancies reveal that the cataloguing of developmental anomalies of the female reproductive system needs further discussion. 
The most common signs/symptoms of the MRKH syndrome are primary amenorrhea and pelvic pain (24), in accordance with the present study. Young girls with vaginal agenesis are often referred to gynaecologists at the beginning of their sex life after experiencing difficulties during sexual intercourse. The most significant in the diagnostic process are various imaging techniques, which aim to visualize not only the gynaecological anomalies, but also associated conditions. The first diagnostic measure is usually ultrasonography, whose main advantages are its promptness and non-invasiveness. It can reveal the missing uterus in the space between the urinary bladder and the rectum (25). On the other hand, ultrasonography may not always detect the uterine buds or ovaries even in ectopic location, it can also falsely identify rectovesical quadrangular structure as hypoplastic uterus; however, the information about rudimentary buds is essential for the assessment of the surgical treatment outcomes (26). Therefore, MRI is considered the optimal imaging tool for the visualization of the rudimentary uterus and associated abnormalities. It has superior diagnostic accuracy without any additional burden (e.g., radiation) so MRI should be offered to all the patients with the MRKH syndrome $(27,28)$. In two patients from our cohort, the diagnosis of MRKH syndrome was accidental during diagnostic laparoscopy or CT scan for surgical indications. It follows that in small number of cases, the diagnosis of MRKH syndrome can be established by a sheer accident.

The treatment goal in these women is the creation of an artificial vagina, either non-surgically or surgically, which will allow a normal sexual function. To date, no randomized controlled trials have been conducted to evaluate and compare the long-term results of the various neovagina creation methods, especially regarding possible subsequent uterus transplantation (29).

Non-surgical methods involve a gradual dilation of the vaginal dimple at the introitus. In some patients with the MRKH syndrome, an adequate vagina can be formed after a repeated natural sexual intercourse, and the use of dilators is a modification of this technique (30). The success of these methods is based on the fact that the perineum is embryologically pliable, and the application of intermittent pressure can create a neocavity (6). This requires time and strong motivation on the side of the patient since the procedure is painful and self-administered. For these reasons, compliance is usually very poor. In our study, we used an active dilation method, the Frank's method, first described in 1938. Frank's procedure is widely used because of its satisfactory results (success rates of about 75-95 \%). The advantages of this method are its low morbidity, absence of surgical complications and its cost-effectiveness. However, there are also disadvantages: it requires long-term dilation (6 months), may be tedious and painful, requires a high motivation, and finally yet importantly, there is also a risk of vaginal apex necrosis. Other complications of the Frank's method include urethritis, cystitis, fistulas, and secondary prolapse (29-32). From our cohort, two patients were able to create a neovagina naturally after a regular sexual intercourse, in three patients, we implemented Frank's method. Based on our results, we can recommend vaginal dilator therapy as the treatment of first choice for the neovagina creation in MRKH syndrome patients. Our recommendation is in line with Callens et al (32), who concluded that with reported high success rates, vaginal dilation should remain the cornerstone of treatment.

The Vecchietti's technique, developed by Vecchietti in the 1960s, is performed by application of two threads that course sub peritoneally, cross the vesicorectal space, and connect to a traction device placed suprapubically with an acrylic olive placed in the vaginal dimple. The constant traction exerted on the olive by the traction device creates a deep invagination of the vesicorectal space in 7 to 8 days. Daily application of apposite dilators for the following weeks allows the creation of a neovagina comparable in size to a normal vagina (33). With an anatomical success rate of 97-99\%, the neovagina retains an adequate size even in the absence of regular sexual intercourse, and there is no need for long-term dilation. The procedure is fast, effective, and minimally traumatic, with low rates of long-term complications (29). From our cohort, we chose this surgical procedure in four patients, with satisfactory results in all cases. The neovagina created in the Vecchietti's procedure has been shown to have a mucosa almost identical to that of a normal vagina, with a glycogensecreting epithelium and the presence of lactobacilli responsible for lactic acid production (33). Interestingly, the study conducted on a cohort of patients from the Czech Republic found out that as many as 62 percent of the patients, who were treated surgically with Vecchietti's method were also willing to undergo uterine transplantation (34). Another important aspect to consider is that the patients, who underwent the surgical procedure had greater vaginal lengths and higher sexual satisfaction and also a higher sexual activity, compared to those treated with the non-surgical approach (35). On the other hand, the Committee on Adolescent Health Care clearly stated that: "Non-surgical vaginal elongation by dilation should be the first-line approach” (36), underscoring our conclusion in the previous paragraph. We have to add that the four patients in our cohort treated with Vecchietti's surgical technique were also offered the dilation therapy as the method of first choice, in line with the recommendations of the Committee on Adolescent Health Care. However, considering that their vaginal length was under $1 \mathrm{~cm}$, all four patients expressed a concern over the failure of this technique and ensuing psychological trauma. They considered the Vecchietti's surgical technique more trustworthy. Knowing how sensitive the neovagina creation is from a patient's perspective and what serious consequences the potential failure would bring, we decided to comply with the patients' wishes, accepted their request, and performed the surgery.

\section{Conclusions and further perspectives}

MRKH syndrome is a congenital anomaly caused by a combination of the genetic predispositions and the environmental factors. It also has important social, psychological, and ethical aspects; thus, it can be considered a multi-dimensional condition, whose complex management requires a tight cooperation between various medical professions. In the present study, we summarized the current knowledge regarding the development of the female repro- 
ductive organs, diagnostic approaches and treatment modalities of MRKH syndrome patients. Satisfactory results in the attempt to create a neovagina can be obtained by both the non-surgical and surgical methods. However, it is necessary to emphasize that one of the major limitations in the assessment of the treatment outcomes is the lack of data on long-term sexual satisfaction related to vaginal length. We can summarize that the modern medicine provides many therapeutic measures, which make it possible for the affected women to have a normal sexual life.

Moreover, there are also techniques giving these patients a chance to become biological mothers of their own children, so they can live a life with all the important needs of a woman satisfied. Nowadays, there are many growing fields like tissue engineering which may also give a hope to MRKH patients trying to conceive. An engineered uterus would be a perfect option, because it deals with many classic problems of organ transplantation. However, most of the research in this area has been conducted on animal models, so a routine clinical application of this approach in human subjects is still out of reach (37).

\section{References}

1. Robbins JB, Broadwell C, Chow LC, Parry JP, Sadowski EA. Müllerian duct anomalies: embryological develop-ment, classification, and MRI assessment. J Magn Reson Imaging 2015; 41 (1): 1-12.

2. Wilson D, Bordoni B. Embryology, Mullerian Ducts (Paramesonephric Ducts). In: StatPearls. Treasure Island (FL): StatPearls Publishing; 2020.

3. Mullen RD, Behringer RR. Molecular genetics of Müllerian duct formation, regression and differentiation. Sex Dev 2014; 8 (5): 281-296.

4. Roly ZY, Backhouse B, Cutting A, Tan TY, Sinclair AH, Ayers KL, Major AT, Smith CA. The cell biology and molecular genetics of Müllerian duct development. Wiley Interdiscip Rev Dev Biol 2018; 7 (3): e310.

5. Liszewska-Kapłon M, Strózik M, Kotarski Ł, Bagłaj M, Hirnle L. Mayer-Rokitansky-Küster-Hauser syndrome as an interdisciplinary problem. Adv Clin Exp Med 2020; 29 (4): 505-511.

6. Choussein S, Nasioudis D, Schizas D, Economopoulos KP. Mullerian dysgenesis: a critical review of the literature. Arch Gynecol Obstet 2017; 295 (6): 1369-1381.

7. Hatim H, Zainuddin AA, Anizah A, Kalok A, Daud T, Ismail A, Nurazurah AG, Grover S. The Missing Uterus, the Missed Diagnosis, and the Missing Care. Mayer-Rokitansky-Küster-Hauser Syndrome in the Lives of Women in Malaysia. J Pediatr Adolesc Gynecol 2020; S10833188(20)30362-4.

8. Fontana L, Gentilin B, Fedele L, Gervasini C, Miozzo M. Genetics of Mayer-Rokitansky-Küster-Hauser (MRKH) syndrome. Clin Gen 2017; 91 (2): 233-246.

9. Georgopapadakos N, Manoli A, Passia G, Skandalakis PN, Filippou D. Uterus Transplantation as a Therapy Method in Mayer-RokitanskyKüster-Hauser Syndrome. Cureus 2019; 11 (12): e6333.

10. Song S, Chen N, Duan YP, Kang J, Deng S, Pan HX, Zhu L. Anxiety symptoms in patients with Mayer-Rokitansky-Küster-Hauser syndrome: a cross-sectional study. Chin Med J 2020; 133 (4): 388-394.

11. Chen N, Song S, Duan Y, Kang J, Deng S, Pan H, Zhu L. Study on depressive symptoms in patients with Mayer-Rokitansky-Küster-Hauser syndrome: an analysis of 141 cases. Orphanet J Rare Dis 2020; 15 (1): 121.
12. Weijenborg P, Kluivers KB, Dessens AB, Kate-Booij MJ, Both S. Sexual functioning, sexual esteem, genital self-image and psychological and relational functioning in women with Mayer-Rokitansky-Küster-Hauser syndrome: a case-control study. Hum Reprod 2019; 34 (9): 16611673.

13. Friedler S, Grin L, Liberti G, Saar-Ryss B, Rabinson Y, Meltzer S. The reproductive potential of patients with Mayer-Rokitansky-KüsterHauser syndrome using gestational surrogacy: a systematic review. Reprod Biomed Online 2016; 32 (1): 54-61.

14. Raziel A, Friedler S, Gidoni Y, Ben Ami I, Strassburger D, Ron-EI R. Surrogate in vitro fertilization outcome in typical and atypical forms of Mayer-Rokitansky-Kuster-Hauser syndrome. Hum Reprod 2012; 27 (1): 126-130.

15. Kisu I, Banno K, Mihara M, Iida T, Yoshimura Y. Current status of surrogacy in Japan and uterine transplantation research. Eur J Obstet Gynecol Reprod Biol 2011; 158 (2): 135-140.

16. Ejzenberg D, Andraus W, Baratelli Carelli Mendes LR, Ducatti L, Song A, Tanigawa R, Rocha-Santos V, Macedo Arantes R, Soares JM Jr, Serafini PC, Bertocco de Paiva Haddad L, Pulcinelli Francisco R, Carneiro D'Albuquerque LA, Chada Baracat E. Livebirth after uterus transplantation from a deceased donor in a recipient with uterine infertility. Lancet 2019; 392 (10165): 2697-2704.

17. Brännström M, Dahm-Kähler P, Kvarnström N, Akouri R, Rova K, Olausson M, Groth K, Ekberg J, Enskog A, Sheikhi M, Mölne J, Bokström H. Live birth after robotic-assisted live donor uterus transplantation. Acta Obstet Gynecol Scand 2020; 99 (9): 1222-1229.

18. Huang Y, Ding X, Chen B, Zhang G, Li A, Hua W, Zhou D, Wang X, Liu D, Yan G, Zhang C, Zhang J. Report of the first live birth after uterus transplantation in People's Republic of China. Fertil Steril 2020; 114 (5): 1108-1115.

19. Patnaik SS, Brazile B, Dandolu V, Ryan PL, Liao J. Mayer-Rokitansky-Küster-Hauser (MRKH) syndrome: a historical perspective. Gene 2015; 555 (1): 33-40.

20. Eisner BH, Bloom DA. Wolff and Müller: fundamental eponyms of embryology, nephrology and urology. J Urol 2002; 168 (2): 425-428.

21. FIPAT. Terminologia Embryologica. Available online: http://fipat.library.dal.ca/te2/ (accessed on 24 December 2020).

22. Acién P, Acién M. Diagnostic imaging and cataloguing of female genital malformations. Insights Imaging 2016; 7 (5): 713-726.

23. Acién P, Acién M. The presentation and management of complex female genital malformations. Hum Reprod Update 2016; 22 (1): 48-69.

24. Goyal LD, Dhaliwal B, Singh P, Ganjoo S, Goyal V. Management of Mullerian Development Anomalies: 9 Years' Experience of a Tertiary Care Center. Gynecol Minim Invasive Ther 2020; 9 (2): 81-87.

25. Chmel R Jr, Pastor Z, Mužík M, Brtnický T, Nováčková M. Syndrome Mayer-Rokitansky-Küster-Hauser - uterine and vaginal agenesis: current knowledge and therapeutic options. Ceska Gynekol 2019; 84 (5): 386-392.

26. Boruah DK, Sanyal S, Gogoi BB, Mahanta K, Prakash A, Augustine A, Achar S, Baishya H. Spectrum of MRI Appearance of MayerRokitansky-Kuster-Hauser (MRKH) Syndrome in Primary Amenorrhea Patients. J Clin Diagn Res 2017; 11 (7): TC30-TC35.

27. Gündoğdu E, Emekli E, Oğuzman M, Kebapçı M. Evaluation of the abdominopelvic region using MRI in patients with primary amenorrhea. J Pediatr Endocrinol Metab 2019; 32 (9): 995-1003. 
28. Wang Y, He YL, Yuan L, Yu JC, Xue HD, Jin ZY. Typical and atypical pelvic MRI characteristics of Mayer-Rokitansky-Küster-Hauser syndrome: a comprehensive analysis of 201 patients. Eur Radiol 2020; 30 (7): 4014-4022.

29. Kölle A, Taran FA, Rall K, Schöller D, Wallwiener D, Brucker SY. Neovagina creation methods and their potential impact on subsequent uterus transplantation: a review. BJOG 2019; 126 (11): 1328-1335.

30. Edmonds DK, Rose GL, Lipton MG, Quek J. Mayer-RokitanskyKüster-Hauser syndrome: a review of 245 consecutive cases managed by a multidisciplinary approach with vaginal dilators. Fertil Steril 2012; 97 (3): 686-690.

31. Gargollo PC, Cannon GM Jr, Diamond DA, Thomas P, Burke V, Laufer MR. Should progressive perineal dilation be considered first line therapy for vaginal agenesis? J Urol 2009; 182 (Suppl 4): 1882-1889.

32. Callens N, De Cuypere G, Wolffenbuttel KP, Beerendonk CC, van der Zwan YG, van den Berg M, Monstrey S, Van Kuyk ME, De Sutter P, Belgian-Dutch Study Group on DSD, Dessens AB, Cools M. Long-term psychosexual and anatomical outcome after vaginal dilation or vaginoplasty: a comparative study. J Sex Med 2012; 9 (7): 1842-1851.

33. Fedele L, Bianchi S, Berlanda N, Fontana E, Raffaelli R, Bulfoni A, Braidotti P. Neovaginal mucosa after Vecchietti's laparoscopic opera- tion for Rokitansky syndrome: structural and ultrastructural study. Am J Obstet Gynecol 2006; 195 (1): 56-61.

34. Chmel R, Novackova M, Pastor Z, Fronek J. The Interest of Women with Mayer-Rokitansky-Küster-Hauser Syndrome and Laparoscopic Vecchietti Neovagina in Uterus Transplantation. J Pediatr Adolesc Gynecol 2018; 31 (5): 480-484.

35. Dabaghi S, Zandi M, Ilkhani M. Sexual satisfaction in patients with Mayer-Rokitansky-Küster-Hauser syndrome af-ter surgical and non-surgical techniques: a systematic review. Int Urogynecol J 2019; 30 (3): 353-362.

36. Committee on Adolescent Health Care. ACOG Committee Opinion No. 728: Müllerian Agenesis: Diagnosis, Manage-ment, And Treatment. Obstet Gynecol 2018; 131 (1): e35-e42.

37. Simopoulou M, Sfakianoudis K, Tsioulou P, Rapani A, Giannelou P, Kiriakopoulos N, Pantou A, Vlahos N, Anifandis G, Bolaris S, Pantos K, Koutsilieris M. What will the future hold for artificial organs in the service of assisted reproduction: prospects and considerations. Front Med 2019; 13 (6): 627-638.

Received March 7, 2021. Accepted June 22, 2021. 